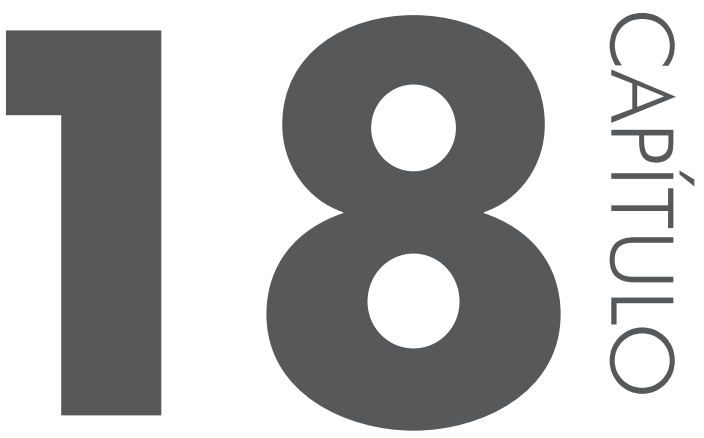

\title{
PSICOLOGIA E EJA: APROXIMAC̣ÕES EM BUSCA DE NOVAS POSSIBILIDADES DE VIDA
}

\author{
Tânia Maia Barcelos ${ }^{1}$ \\ Carine Almeida Andrade ${ }^{2}$ \\ Micaela Brandão Póvoa ${ }^{3}$ \\ Wanderson dos Santos Ribeiro ${ }^{4}$ \\ Elilany Elias Silva
}

1 Professora Adjunta do Curso de Psicologia, Unidade Acadêmica Especial de Biotecnologia, Universidade Federal de Goiás/Regional Catalão, Catalão/GO, Brasil

2 Bolsista do PIBID de Psicologia, Unidade Acadêmica Especial de Biotecnologia, Universidade Federal de Goiás/Regional Catalão, Catalão/GO, Brasil

3 Bolsista do PIBID de Psicologia, Unidade Acadêmica Especial de Biotecnologia, Universidade Federal de Goiás/Regional Catalão, Catalão/GO, Brasil

4 Bolsista do PIBID de Psicologia, Unidade Acadêmica Especial de Biotecnologia, Universidade Federal de Goiás/Regional Catalão, Catalão/GO, Brasil

5 Bolsistado PIBID de Psicologia, Unidade Acadêmica Especial de Biotecnologia, Universidade Federal de Goiás/Regional Catalão, Catalão/GO, Brasil

E-mail de contato: taniamaia.barcelos@gmail.com 
Resumo: Esse trabalho visa apresentar as experiências do Programa Institucional de Bolsa de Iniciação à Docência (PIBID) de Psicologia da Universidade Federal de Goiás/Regional Catalão desenvolvidas na Educação de Jovens e Adultos (EJA) do Colégio Estadual Maria das Dores Campos, em 2014, buscando incentivar a docência na área e contribuir com os processos de formação dos estudantes. As aproximações com a Educação de Jovens e Adultos levaram a conhecer as trajetórias, as formas de convivência, as perspectivas dos alunos e a perceber a urgência de outras possibilidades de vida no ambiente escolar, marcado por cansaço, desânimo e diferentes formas de exclusão social. Realizamos sete encontros com os alunos do último semestre e a metodologia utilizada foi a roda de conversa por meio de textos literários, músicas, vídeos e filme brasileiro. Tais recursos ajudaram a pensar questões significativas da produção de subjetividade e a arejar a sala de aula, propiciando momentos de alegria, afirmação do presente e ressignificação de histórias de vida. Nesse processo, construímos diálogos que poderão despertar novos caminhos e trajetórias profissionais. Com esse trabalho, percebemos a importância do PIBID para a formação do professor de Psicologia e do psicólogo, que tem enfrentado desafios urgentes na tentativa de compreender os processos educativos e psicossociais no contexto da atualidade.

Palavras-chave: Psicologia. EJA. PIBID. Subjetividade.

Abstract: This work presents the experiences of the PIBID of Psychology in Federal University of Goiás/Regional Catalão developed in the Youth and Adult Education (EJA) of State College Maria das Dores Campos, in 2014, seeking to encourage teaching in the area and contribute with the formation process of the students. The approximations with the EJA led to know the trajectories, forms of coexistence, the prospects of students and to realize the urgency of other possibilities of life in the school environment, marked by tiredness, dismay and various forms of social exclusion. We conducted seven meetings with students last semester and the methodology used was the conversation wheel through literary texts, music, videos and Brazilian film. These resources helped to think significant issues of subjectivity production and aerate the classroom, providing moments of joy, affirmation of the present and re-signification of life stories. In this process, we build dialogues that will be able to arouse new paths and professional trajectories. With this work we realize the importance of PIBID for the formation of psychology teacher and of the psychologist, who have faced urgent challenges in trying to understand educational processes and psychosocial in the context today.

Keywords: Psychology. EJA. PIBID. Subjectivity.

\section{INTRODUC̣ÃO}

Este artigo decorre de experiências realizadas, em 2014, no Programa Institucional de Bolsa de Iniciação à Docência (PIBID) do Curso de Psicologia da 
Universidade Federal de Goiás/Regional Catalão (UFG/RC). O projeto se iniciou em 2012 e é desenvolvido em parceria com o Colégio Estadual Maria das Dores Campos, localizado no Bairro Ipanema da cidade de Catalão/Goiás, sudeste goiano, com mais de 90 mil habitantes. É executado por uma equipe composta por oito bolsistas: seis estudantes, uma docente do curso de Psicologia e uma professora/supervisora da rede estadual de ensino do estado de Goiás.

O PIBID é um programa financiado pela Coordenação de Aperfeiçoamento de Pessoal de Nível Superior (Capes), Fundação do Ministério da Educação (MEC), que visa incentivar a formação de professores para a Educação Básica, concedendo bolsas a alunos de licenciatura, participantes de projetos de iniciação à docência, desenvolvidos por Instituições de Educação Superior (IES) em parceria com escolas de Educação Básica da rede pública de ensino. Os subprojetos devem promover a inserção dos estudantes no contexto das escolas públicas orientados por um docente da licenciatura e um professor da escola básica ${ }^{6}$.

As ações discutidas neste artigo foram realizadas na Educação de Jovens e Adultos (EJA), no período noturno, especificamente, em duas turmas do quarto semestre, ou seja, no último período dessa modalidade de ensino. Escolhemos essas turmas em função da proximidade do término da Educação de Jovens e Adultos, porque nesse momento emergem questões fundamentais para os estudantes, sobretudo, relacionadas ao tempo - presente, passado e futuro. Nesse momento, é comum se perguntarem o que fazer depois, se continuarão seus estudos, se o diploma poderá ajudá-los a encontrar novas perspectivas de trabalho.

Com as ações desenvolvidas, buscamos conhecer a realidade da escola pública, aproximar a Universidade da Educação Básica, incentivar a docência em Psicologia, contribuir com as reflexões de temas transversais e ampliar a formação dos estudantes da Educação de Jovens e Adultos, bem como a formação continuada da professora da escola parceira.

O interesse do PIBID de Psicologia pela Educação de Jovens e Adultos decorre de experiências anteriores realizadas no estágio da licenciatura, que prevê a presença dos estudantes, prioritariamente, na escola pública. Embora a Psicologia não esteja, formalmente, no currículo da Educação de Jovens e Adultos, podemos afirmar que ela tem sido um espaço significativo de inserção dos estudantes e possibilitado diversos debates e reflexões na sala de aula. Nas atividades de estágio, temos abordado várias temáticas relacionadas com a produção de subjetividade (saúde mental, qualidade de vida, ética, exclusão social, formas de convivência

6 Para mais informações, conferir o site do programa: <http://www.capes.gov.br/educacao-basica/ capespibid>. Acesso em 20 set. 2015. 
com o outro etc $)^{7}$, procurando atender as demandas apresentadas pelos estudantes da Educação de Jovens e Adultos e pelos professores da escola campo, a qual tem mostrado interesse na continuidade do trabalho e na construção de novas parcerias com o curso de Psicologia da UFG/Regional Catalão.

As experiências decorrentes do estágio da licenciatura em psicologia têm despertado a necessidade de outras aproximações com a realidade da Educação de Jovens e Adultos, carente de novas políticas públicas que visem garantir mais qualidade nos processos de formação dos estudantes. Nesse sentido, a proposta do PIBID de Psicologia da UFG/Regional Catalão, atento às necessidades da escola parceira, propôs a realização de atividades na sala de aula com o objetivo de promover reflexões sobre alguns aspectos considerados fundamentais nos processos educativos. É importante, por exemplo, afirmar as histórias de vida dos estudantes, suas trajetórias e perspectivas futuras, principalmente, no final da Educação de Jovens e Adultos, momento de conclusão de mais uma etapa do processo de escolarização, marcada por alegrias e novas expectativas.

Afinados com os objetivos gerais do PIBID, buscamos construir espaços de discussão e de expressão da subjetividade em uma escola pública, aberta à comunidade e às classes populares que necessitam de parcerias com a universidade, sobretudo, na perspectiva do compromisso social com a transformação da vida nas dimensões macro e micropolíticas, indispensáveis para a construção de uma sociedade acolhedora de novas possibilidades de existência.

\section{ASPECTOS HISTÓRICOS DA EDUCAC̣ÃO DE JOVENS E ADULTOS}

Antes de discutirmos as ações do PIBID de Psicologia, consideramos importante apresentar, de forma breve, uma perspectiva histórica da Educação de Jovens e Adultos no Brasil que, segundo Sampaio (2009), está marcada por tensões entre diferentes projetos de sociedade e diferentes ideias sobre as finalidades da educação. Historicamente, a relação de domínio e humilhação, estabelecida entre a elite e as classes populares no Brasil, perdura em muitos documentos oficiais que ainda parecem tratar a Educação de Jovens e Adultos como um favor e não como o pagamento de uma dívida social. Como expressão dessa história de tensões e ambiguidades, ainda, hoje, sobressai a função supletiva compensatória da Educação de Jovens e Adultos (educação para pessoas que não tiveram o direito à escola antes da vida adulta), apesar do discurso sobre o direito à educação permanente para todos, intensificado a partir da década de 1990.

7 Algumas experiências do estágio da licenciatura foram apresentadas e discutidas no artigo: Experiências da Psicologia na EJA: o estágio de licenciatura da UFG/Campus Catalão. In: Olhares \& Trilhas, ano XVI, n. 19 (jan./jun), p. 22-32, 2014. 
Ribeiro et al. (2001) afirma que no Brasil, o início da Educação Básica para os adultos, ocorre a partir da década de 1930, quando começa a consolidação de um sistema público de educação elementar no país. Esse movimento incluiu esforços articulados para a extensão do ensino elementar aos adultos, especialmente nos anos de 1940.

Neste período, a sociedade brasileira passava por grandes transformações, associadas ao processo de industrialização e concentração populacional em centros urbanos. A oferta de ensino básico gratuito estendia-se consideravelmente, acolhendo setores sociais cada vez mais diversos. A ampliação da educação elementar foi impulsionada pelo governo federal, que traçava diretrizes educacionais para todo o país, determinando as responsabilidades dos estados e municípios (RIBEIRO et al., 2001, p. 19).

Assim, no final da década de 1940, com o fim da ditadura de Vargas, o país vivia uma efervescência política de redemocratização e a Segunda Guerra Mundial alertava para a urgência de integrar os povos visando à paz e à democracia. Tais fatores contribuíram para que a educação dos adultos ganhasse destaque. Além disso, era necessário aumentar as bases eleitorais para a sustentação do governo, integrar os imigrantes recentes e incrementar a produção.

Nesse contexto, Conforme Ribeiro et al. (2001), a educação de adultos define sua identidade tomando a forma de uma campanha nacional de massa, a Campanha de Educação de Adultos (lançada em 1947), que conseguiu resultados significativos, articulando e ampliando os serviços já existentes e estendendo-os às diversas regiões. Em um curto período de tempo, foram criadas várias escolas supletivas, mas o clima de entusiasmo começou a diminuir na década de 1950. Algumas iniciativas não tiveram sucesso e a campanha se extinguiu antes do final da década. "Nesse momento, o analfabetismo era concebido como causa e não efeito da situação econômica, social e cultural do país. Essa concepção legitimava a visão do adulto analfabeto como incapaz e marginal, identificado psicológica e socialmente com a criança” (RIBEIRO et al., 2001, p. 20).

As críticas à Campanha de Educação de Adultos dirigiam-se às suas deficiências administrativas, financeiras e à sua orientação pedagógica. A superficialidade do aprendizado, a inadequação do método para a população adulta e para as diferentes regiões do país foram questionadas. As críticas convergiam para uma nova visão sobre o analfabetismo e para a consolidação de um novo paradigma pedagógico para a educação de adultos, cuja referência principal foi o educador pernambucano Paulo Freire. Esse novo paradigma da educação baseado nos ideais propostos por Paulo Freire passou a levar em conta o aluno, seu contexto histórico e sua cultura.

"O paradigma pedagógico que se construiu nessas práticas baseava-se num novo entendimento da relação entre a problemática educacional e a problemática 
social. Antes apontado como causa da pobreza e da marginalização, o analfabetismo passou a ser interpretado como efeito da situação de pobreza gerada por uma estrutura social não igualitária" (RIBEIRO et al., 2001, p. 23). Nesse paradigma, além da dimensão social e política, havia, também, um forte componente ético, implicando um profundo comprometimento do educador com os educandos. Nesse sentido, Paulo Freire criticou a educação bancária (que considerava o analfabeto uma espécie de gaveta vazia, na qual o educador deveria depositar os conhecimentos) e tomou o educando como sujeito de sua aprendizagem, propondo uma ação educativa que não negasse a sua cultura, mas a transformasse por meio do diálogo. Para Quintal Freitas (2007, p. 52),

[...] o que se vê, aqui nesta época em especial, é uma íntima relação entre três aspectos que levam a uma politização da consciência, a saber, entre: alfabetização-educação popular-participação e conscientização. Neste tripé, a ação e a prática populares desempenham um papel importante, ancoradas na assessoria de diferentes naturezas que os profissionais liberais e os intelectuais forneceram a estes movimentos. Esta ligação - ou seja, falar em alfabetização significava na época, também, falar em educação popular e conscientização - mantém-se ainda por alguns anos, nas décadas seguintes, quase permanecendo junta até o final do período do governo de exceção, quando então divisam-se outras possibilidades e anunciam-se outras definições epistemológicas para cada um destes campos e para os diversos movimentos populares e sociais até então.

A partir do golpe militar, de 1964, os programas de alfabetização e educação popular e seus promotores, vistos como grave ameaça à ordem, foram duramente reprimidos. O governo passou a permitir a realização de programas de alfabetização de adultos na perspectiva assistencialista e conservadora. Assim, em 1967, foi lançando o Movimento Brasileiro de Alfabetização (Mobral) que se constituiu como organização autônoma, em relação ao Ministério da Educação, contando com um volume significativo de recursos. Durante a década de 1970, o movimento foi expandido pelo território nacional (RIBEIRO et al., 2001).

Na década de 1980, com o início da abertura política do país e da emergência dos movimentos sociais, o Mobral foi extinto e muitas experiências de alfabetização ganharam consistência, fortalecendo a proposta de alfabetização conscientizadora dos anos de 1960 e os estudos de educadores comprometidos com as lutas populares. Na Constituição Federal de 1988 foi assegurado o direito à Educação Básica a jovens e adultos como resultado das mobilizações dos setores progressistas no processo constituinte. O governo federal e a sociedade civil deveriam se mobilizar para erradicar o analfabetismo em 10 anos.

Segundo Ribeiro et al. (2001), a história da educação de jovens e adultos no Brasil chega à década de 1990, reclamando da consolidação de reformulações pedagógicas necessárias ao Ensino Fundamental. O número de jovens e adultos excluídos do sistema regular ressaltava os desafios para garantir a esse segmento 
social marginalizado um acesso à cultura letrada que lhe possibilitasse uma participação mais ativa no mundo do trabalho, da política e da cultura.

Essa década, conforme Szanto (2006), foi marcada por retrocessos nas políticas públicas de educação de adultos e pelo Estado eximindo-se de sua responsabilidade, passando-a para as ONGs. No final dessa década houve aproximações entre ONGs e o Estado, por meio da política de parceria, mas sem investimento financeiro do governo em políticas públicas de educação de jovens e adultos. A década foi marcada, também, por um evento internacional, a Conferência Mundial da Educação para Todos, ocorrida, em 1990, na Tailândia, em que países e entidades internacionais comprometeram-se a realizar esforços para enfrentar os problemas educacionais de crianças, jovens e adultos no mundo.

Em 2003, no governo de Luiz Inácio Lula da Silva, foi lançado o programa Analfabetismo Zero (depois chamado de Brasil Alfabetizado) que tinha como objetivo erradicar o analfabetismo no país. "Mencionado como uma prioridade do governo, ao lado do combate à pobreza, a Educação de Jovens e Adultos volta a ser tema de políticas públicas e o diálogo com a sociedade civil e especialistas é retomado" (SZANTO, 2006, p. 24). Apesar disso, como afirma Szanto (2006), a Educação de Jovens e Adultos "nunca foi considerada uma prioridade para o governo e que, por este motivo, não se constitui ainda hoje como um componente efetivo e fundamental do sistema educacional do país" (SZANTO, 2006, p. 26).

Isso indica que ainda há muito por ser feito e muitas outras lutas deverão ser travadas nesse campo, se quisermos construir uma educação de qualidade para todas as pessoas do nosso país, sobretudo, para muitos jovens que tiveram a entrada precoce no mundo do trabalho (formal e informal) e, em função de vários motivos, foram excluídos do processo de escolarização.

\section{ASPECTOS METODOLÓGICOS E DISCUSSÕES SOBRE AS PRÁTICAS REALIZADAS NA ESCOLA}

Após contatos iniciais com os alunos, foram realizados sete encontros com duas turmas do quarto semestre da Educação de Jovens e Adultos, os quais contaram com a presença dos estudantes de Psicologia e da professora/supervisora do projeto. Os encontros foram planejados em reuniões semanais com a colaboração de todos os integrantes do projeto.

A metodologia utilizada nos encontros foi a da roda de conversa que, segundo Afonso e Abade (2008), é uma forma de trabalho que incentiva a participação e a reflexão, facilitando as condições para o diálogo entre os participantes, a escuta e a circulação da palavra. Além disso, a roda de conversa favorece o uso de técnicas de dinamização de grupo e pode ser utilizada em diversos contextos, tais como escolas, postos de saúde, associações comunitárias e outros. 
Nas rodas de conversa realizadas na escola utilizamos textos literários, canções, um vídeo e um filme brasileiro. Optamos por esse caminho por entender, a partir de Kastrup (2005), que a arte favorece o aprendizado como experiência de problematização e força a pensar. "A arte não transmite informação, mas provoca perturbação. Ela mobiliza uma atenção de qualidade distinta daquela envolvida na execução de uma tarefa. O aprendizado da arte não se esgota na aquisição de respostas e de regras" (KASTRUP, 2005, p. 2). A relação com a arte caracteriza-se por experiências de estranhamento que deslocam o eu e mobilizam uma atenção aberta ao plano dos afetos. Como afirma a autora, aprendemos com nossos alunos e os alunos aprendem uns com os outros. Dispositivos como um livro, um filme ou uma imagem podem ensinar. Nesse sentido, o processo de ensino-aprendizagem configura-se como uma rede complexa e sem lugares pré-definidos. "Não há via de mão única. As trocas se dão em múltiplas direções, envolvendo diversos atores, formais e informais" (KASTRUP, 2005, p. 2).

No primeiro encontro realizado, os alunos da Educação de Jovens e Adultos foram bastante acolhedores, o que facilitou a apresentação da nossa proposta de trabalho e, também, o desenvolvimento dos encontros posteriores que necessitavam da participação e colaboração de todos. Após o primeiro encontro, perguntamo-nos quem eram aqueles alunos, porque estavam ali e o que esperavam da formação na Educação de Jovens e Adultos. Acreditávamos que as aulas pudessem ser espaços de reflexão sobre essas perguntas que envolvem a relação com o tempo, com o outro e consigo mesmo. Apostávamos na ideia de que a reflexão sobre esses desafios ajudaria, de alguma maneira, a enfrentar os processos de aprendizado na escola, lugar de contradições, reprodução, produção e desconstrução de conhecimentos e subjetividades.

No segundo encontro, propusemos reflexões sobre uma velha e complexa pergunta (quem sou eu?), compreendendo que é impossível respondê-la, uma vez que não concebemos as identidades como sendo fixas, estáveis e imutáveis. Apostamos em uma subjetividade produzida por instâncias individuais, coletivas e institucionais. Essa produção ocorre de forma industrial e maquinal, em todos os níveis da produção e do consumo (GUATTARI, 1992). As máquinas tecnológicas de informação e comunicação operam no núcleo da subjetividade, não apenas na memória, inteligência, mas, também, na sensibilidade, nos afetos e nos fantasmas inconscientes. Nesse sentido, a questão central, para nós, hoje, é como produzir novos agenciamentos de singularização que visem mudanças da vida no plano cotidiano e dos grandes conjuntos econômicos e sociais, ou seja, como produzir novas formas de subjetividade, recusando os modos de "encodificação" preestabelecidos, de manipulação e de telecomando. Recusá-los, "para construir, de certa forma, modos de sensibilidade, modos de relação com o outro, modos de produção, modos de criatividade que produzam uma subjetividade singular" (GUATTARI; ROLNIK, 1986, p. 17). 
Com a pergunta proposta, inicialmente, esperávamos que os alunos da Educação de Jovens e Adultos partilhassem aspectos de suas histórias de vida e problematizassem a relação que estabelecem com o tempo - passado, presente e futuro. Para nos ajudar a pensar a questão, utilizamos dois poemas: "Minha cidade" (de Cora Coralina) e "Quem sou eu?" (de Pedro Bandeira). Entregamos os poemas para cada um e os lemos juntos, em voz alta. Destacamos os aspectos que mais chamaram a nossa atenção e buscamos relacioná-los com as vidas dos estudantes. Desse modo, os poemas facilitaram a conversa com os alunos da Educação de Jovens e Adultos e possibilitaram a reflexão de questões importantes no campo da produção de subjetividade.

A partir do poema de Cora Coralina discutimos que somos constituídos também pelos diversos lugares que habitamos e assumimos diferentes versões de nós mesmos ao longo da vida.

Eu sou aquela mulher

que ficou velha, esquecida, nos teus larguinhos e nos teus becos tristes [...]

Eu sou aquele teu velho muro verde de avencas $[\ldots]$

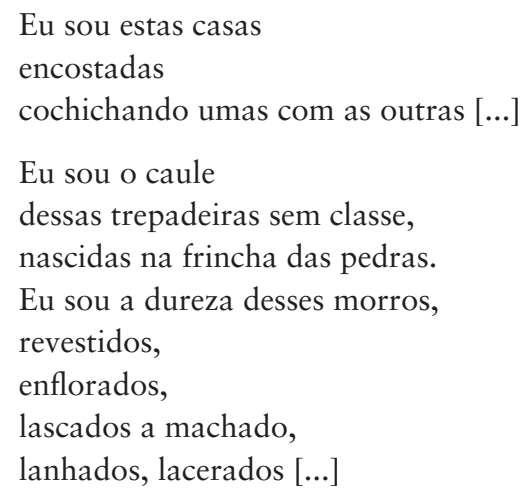

A leitura e a discussão do poema levaram-nos a perceber que somos o que vivemos concretamente, mas também atualizamos potencialidades que nos atravessam e nos tornam outros. Produzimos novas formas de subjetividade e recusamos os assujeitamentos que massificam, excluem e estigmatizam as diferenças, como afirmam Bock, Furtado e Teixeira (2009). Nesse sentido, consideramos que as questões discutidas, a partir do poema de Cora Coralina, são importantes para os alunos da Educação de Jovens e Adultos que são, geralmente, marcados pela dureza da vida, pelo cansaço cotidiano e pela exclusão social. 
Os aspectos abordados no poema "Minha cidade" ajudaram a perceber a necessidade de afirmação das histórias de vida, que são diferentes e carregadas de marcas socioculturais singulares. As histórias de vida ajudam a compreender o presente e a vislumbrar experiências futuras. Nesse momento, lembramos que somos vários e que constituímos nossas existências considerando os diversos lugares/tempos, encontros e desencontros vividos.

Tais reflexões auxiliaram-nos a perceber que não somos determinados pelas histórias vividas concretamente, uma vez que há linhas de escape que nos atravessam e nos fazem querer que tudo seja diferente, como sugere Pedro Bandeira no segundo poema ("Quem sou eu?") trabalhado com os alunos da Educação de Jovens e Adultos.

Nesse poema, o poeta pergunta se as pessoas são quem são ou são o que elas têm.

\author{
Eu queria que comigo \\ Fosse tudo diferente \\ Se alguém pensasse em mim, \\ Soubesse que eu sou gente \\ Falasse do que eu penso, \\ Lembrasse do que eu falo, \\ Pensasse no que eu faço \\ Soubesse por que me calo! \\ Porque eu não sou o que visto \\ Eu sou do jeito que estou! \\ Não sou também o que eu tenho \\ Eu sou mesmo quem eu sou!
}

O poema gerou diversas discussões sobre a nossa relação com a mídia, com o consumo e, também, como, na sociedade capitalista, somos percebidos pelo que temos e pelo que comemos, somos vistos pela roupa que usamos, pelo lugar onde trabalhamos, pelo diploma que conquistamos etc. Assim, enfatizamos que somos constituídos na/pela cultura e sociedade em que vivemos, de forma que nossas histórias são singulares e carregadas de vivências significativas, as quais nos ajudam a afirmar a nossa história e, ao mesmo tempo, a deixar de reproduzi-las, criando outros percursos e modos de existência. Como afirma Dias, (2010), a partir de Foucault, "as artes da existência situam-se na imanência da história em que as produções de subjetividade se constituem no tempo. É também ali que elas se desfazem e se transformam" (DIAS, 2010, p. 3).

Nesse processo, compreendemos que os textos literários podem fornecer subsídios para a problematização dos modos de subjetivação e ampliar as experiências de si. Como afirmam Boechat e Kastrup (2000), 
[...] a leitura de textos literários possibilita o desenvolvimento de modos de subjetivação ou processos de singularização e maneiras de resistir a modos sobrecodificados preestabelecidos. Tecnologias cognitivas de massa, como a televisão, tendem a difundir a serialização e planificação de subjetividades, apontando para o consumo passivo de imagens, de sistema de representação, de sensibilidade e desejo. (BOECHAT; KASTRUP, 2000, p. 69)

Na contramão da serialização das subjetividades, realizamos a terceira oficina com os alunos da Educação de Jovens e Adultos, buscando promover reflexões sobre o presente. Para isso, fizemos aproximações com as canções "Tente outra vez" (Raul Seixas) e "Tempo perdido" (Legião Urbana). Nesse dia, levamos o violão para a sala de aula e fizemos uma grande roda de cantoria. Cantamos as músicas juntos e depois discutimos as questões que emergiram, as quais problematizavam os desafios, os anseios e as sensações que eles experimentaram no momento em que entraram na Educação de Jovens e Adultos. Perguntamos, também, o que fariam agora que estava próximo o término do curso, com o último semestre da Educação de Jovens e Adultos. Os alunos deveriam dar continuidade às frases propostas: a) quando entrei na Educação de Jovens e Adultos; b) agora, perto do fim da Educação de Jovens e Adultos, eu...

Procuramos, com essa experiência, ouvir os alunos sobre quando iniciaram a Educação de Jovens e Adultos, sobre quais eram as suas expectativas e se elas foram alcançadas ao longo do curso. Além disso, buscamos proporcionar aos alunos um momento de partilha de desejos, de expectativas e de perspectivas quanto ao futuro. Assim, finalizamos a roda de conversa reforçando que as mudanças e as rupturas que ocorrem em nossas vidas permitem a criação de novas formas de existir ou viver; se perdemos determinadas formas de vida, outras poderão ser criadas.

$\mathrm{Na}$ quarta oficina abordamos o tema: politica e vida cotidiana. A escolha do tema ocorreu em função do momento eleitoral de 2014 (eleições para presidente e para senadores/deputados), bastante efervescente e contagiante. Buscamos promover reflexões para além da política partidária, específica do contexto vigente, abordando dimensões macro e micropolíticas da vida cotidiana. Assim, a política foi tratada no sentido amplo do termo, intrinsecamente ligada às decisões e escolhas que norteiam as práticas do dia a dia, inclusive as relações com o outro. Pautamo-nos nos argumentos de Rocha (2011, p. 212) para a qual "acessar micropolíticas transformadoras implica um deslizamento no foco: colocar uma lupa nas relações, nos modos de funcionamento, nas implicações entre as pessoas e destas com o trabalho que realizam".

Para que os alunos pensassem a respeito das micropolíticas do cotidiano, apresentamos o poema "O analfabeto político", de Bertold Brecht, e o vídeo Meninas de Sinhá, que conta a história de um grupo de mulheres criado como espaço alternativo para enfrentar problemas cotidianos como a depressão. Esses 
recursos possibilitaram leituras críticas sobre a realidade local e sobre o momento atual de crescente despolitização da sociedade frente às questões que se apresentam no dia a dia. Além disso, foi possível conversar também sobre as formas de vida contemporânea que têm nos deixado dependentes da utilização excessiva de medicamentos, da televisão, das literaturas de autoajuda e, mais recentemente, do Facebook e do WhatsApp. Como afirma Rolnik (1997), em tempos de globalização, intensificam-se as misturas, pulverizam-se as identidades e o mercado disponibiliza kits de perfis-padrão para serem consumidos, independente do contexto cultural. As drogas disponíveis, que geram uma espécie de toxicomania generalizada, sustentam e produzem demandas de ilusão da subjetividade, tendo em vista manter sua suposta estabilidade e sua forma identitária.

$\mathrm{Na}$ quinta oficina realizada com os alunos da Educação de Jovens e Adultos, apresentamos e discutimos o filme brasileiro Tapete Vermelho (2006). Nosso objetivo era conversar sobre a cultura popular brasileira, sobretudo, a necessidade de valorização do que produzimos e a importância do acesso aos bens culturais como direito de cidadania. Além disso, fizemos breves aproximações de alguns aspectos do personagem principal (que faz uma homenagem ao Mazzaropi) que são semelhantes aos das pessoas que vivem no campo e nas pequenas cidades do interior do país, tais como as formas de linguagem, as crenças e os valores construídos em ambientes específicos. Lembramos, também, o quanto temos utilizado, hoje, linguagens massificadas provenientes da grande mídia, da internet e da publicidade.

Outro ponto levantado, nessa oficina, diz respeito à importância da construção de formas de luta e enfrentamento dos desafios da nossa sociedade, injusta e desigual, que gera adoecimentos e exclusões, muito presentes na história do aluno da Educação de Jovens e Adultos, o qual, geralmente, retorna à escola, depois de vários anos, com poucas motivações e perspectivas futuras. Como afirma Quintal Freitas (2007, p. 59), “Ele 'perdeu' a época ou tempo considerado 'normal' para estudar e, agora, quando vem estudar, já está, em parte, 'ultrapassado' para este tempo do estudo; e embora seja já um adulto e, portanto, mais 'maduro e avançado', acaba apresentando mais e maiores dificuldades nesse processo de aprendizagem do que os mais jovens que estão no 'tempo normal' de estudo".

Para a autora, esse paradoxo gera uma posição de inferioridade e de (auto) desvalorização no aluno da Educação de Jovens e Adultos, trazendo sérias repercussões à dimensão humana e criando uma "não capacidade" e uma "não desenvoltura" para o enfrentamento desses problemas em um mundo que lhe aparece pouco receptivo e amistoso. Os indícios que explicitam isso repercutem de forma negativa e ele procura esconder-se, distanciando-se da escola. "Assim, o educando vive esta perversa dinâmica a cada minuto da sua condição de estudo, mesmo que isto não seja dito, conversado ou discutido. Trata-se de um peso 
psicossocial em que sua baixa autoestima cresce, assim como cresce a descrença que tem em si mesmo, e todo este processo acaba sendo vivido silenciosa e solitariamente" (QUINTAL FREITAS, 2007, p. 60).

Tais aspectos chamaram a nossa atenção no trabalho junto à Educação de Jovens e Adultos. A última oficina foi realizada no dia do encerramento do ano letivo. Nesse dia, oferecemos um lanche para os formandos, fotografamos a festa (que ocorreu na sala de aula), cantamos com eles e conversamos sobre como percebiam esse momento significativo da vida deles. Foi significativo, também, para a equipe do PIBID de Psicologia que partilhou, com os estudantes, instantes de alegria, de descontração e de novos aprendizados. Aprendizado, sobretudo, da afirmação da vida experimentada no presente.

No encerramento de mais uma etapa de escolarização dos alunos da Educação de Jovens e Adultos, destacamos as possibilidades de seguir adiante, a importância de valorização do momento da formatura e, também, do coletivo que fortalece a vida para além da dimensão individual. Aproveitamos a ocasião para cantar, novamente, com os alunos a canção “Tempo Perdido", da banda Legião Urbana, que afirma em seus versos: "não tenho mais o tempo que passou, mas tenho muito tempo. Temos todo o tempo do mundo".

\author{
Todos os dias \\ Antes de dormir \\ Lembro e esqueço \\ Como foi o dia \\ Sempre em frente \\ Não temos tempo a perder [...] \\ Então me abraça forte \\ E diz mais uma vez \\ Que já estamos \\ Distantes de tudo \\ Temos nosso próprio tempo [...] \\ Nem foi tempo perdido \\ Somos tão jovens \\ Tão Jovens
}

\title{
4 CONSIDERAÇÕES FINAIS
}

Concluímos esse trabalho destacando a importância da Licenciatura e do PIBID para a formação em Psicologia, que permitem aproximações com o cotidiano escolar, marcado e permeado por inúmeras histórias, lutas e contradições.

O trabalho realizado na Educação de Jovens e Adultos possibilitou experiências inéditas, vividas por meio dos encontros realizados com os alunos, com os professores e nas reuniões para estudos e planejamentos. O projeto criou opor- 
tunidades para lançarmos novos olhares para esse ambiente/espaço considerado, muitas vezes, pouco motivador e quase sem vida. Não é por acaso que essa palavra está presente nesse texto e insiste em se repetir. Quando propusemos as oficinas, almejamos a criação de um espaço em que a alegria e o encontro com o outro pudessem acontecer efetivamente. Isso foi alcançado em vários momentos.

Pensamos em afirmar histórias de vida e outras possibilidades de relação com o tempo, mais abertas ao futuro, vendo o tempo como campo de novas experimentações. Durante as oficinas, os poemas, as músicas, o vídeo e o filme ajudaram a pensar questões significativas na produção de subjetividade, possibilitando arejar o ambiente da sala de aula. Buscamos propiciar aos alunos momentos de interação e de afirmação de histórias de vida como forma de construção de diálogos que despertam novos caminhos, significações, trajetórias escolares e profissionais.

A realização das oficinas permitiu contribuir para a formação continuada da professora participante do projeto e, também, para fortalecer a Educação de Jovens e Adultos como um campo aberto às diversas áreas do conhecimento, incluindo a Psicologia que não consta formalmente na grade curricular. Acreditamos que os objetivos principais do PIBID de Psicologia foram alcançados a contento e desejamos que esse trabalho seja ponto de partida para novas experimentações na Educação de Jovens e Adultos.

\section{REFERÊNCIAS}

AFONSO, M. L. M; ABADE, F. L. Para reinventar as rodas. Belo Horizonte: Rede de Cidadania Mateus Afonso Medeiros (RECIMAM), 2008. Disponível em: <http://www. novamerica.org.br/medh2/arquivos/reinventar_rodas.pdf>. Acesso em: 28 set. 2015. BARCELOS, T. M. et al. Experiências da Psicologia na EJA: o estágio de licenciatura da UFG/Campus Catalão. Olhares \& Trilhas, Uberlândia, ano XVI, n. 19, p. 22-32, 2014. BOCK, A. M. B.; FURTADO, O.; TEIXEIRA, M. de L. T. (Org.). Psicologias: uma introdução ao estudo de Psicologia. 13. ed. São Paulo: Saraiva, 2002.

BOECHAT, M.; KASTRUP, V. A experiência com a literatura em uma instituição prisional. Psicologia em Revista, Belo Horizonte, v. 15, n. 3, p. 23-40, dez.2009. DIAS, R. de O. Arte que nos move: Oficinas de Formação Inventiva de Professores. $33^{\mathrm{a}}$ Reunião da Anped, 2010. Disponível em: <http://33reuniao.anped.org.br/33encontro/app/ webroot/files/file/Trabalhos\%20em\%20PDF/GT24-6493--Int.pdf>. Acesso em: 19 abr. 2015. GUATTARI, F. Caosmose: um novo paradigma estético. Rio de Janeiro: editora 34, 1992. GUATTARI, F.; ROLNIK, S. Micropolítica: cartografias do desejo. Petrópolis: Vozes, 1986. KASTRUP, V. Ensinar e aprender: falando de tubos, potes e redes. Boletim Arte na Escola, São Paulo, n. 40, 2005. Disponível em: <http://artenaescola.org.br/sala-deleitura/ artigos/artigo.php?id=69347\&>. Acesso 19 abr. 2015. 
LEGIÃO urbana. Tempo Perdido. Dois. Faixa 06. EMI, 1986. LP.

MENINAS de Sinhá. Disponível em: <https://www.youtube.com/ watch?v=OaCPWBSXvVU>. Acesso em: 9 mai. 2015.

MINISTÉRIO DA EDUCAÇÃO/Fundação Capes. Pibid - Programa Institucional de Bolsa de Iniciação à Docência. Disponível em: <http://www.capes.gov.br/ educacaobasicacapespibid>. Acesso em: 9 mai. 2015.

QUINTAL FREITAS, M. de F. Educação de Jovens e Adultos, educação popular e processos de conscientização: intersecções na vida cotidiana. Educar, n. 29, Curitiba: editora UFPR, p. 47-62, 2007.

RIBEIRO, V. M. M. et al. Educação de Jovens e Adultos: proposta curricular para o $1^{\circ}$ segmento do Ensino Fundamental. São Paulo/Brasília: Ação Educativa MEC, 2001. ROCHA, M. L. Desafios da Psicologia e Educação entre a macro e a micropolítica. In: AZZI, R. G.; GIANFALDINI, M. H. T.(Org.). Psicologia e Educação. São Paulo: Casa do Psicólogo, 2011.

ROLNIK, S. B. Toxicômanos de identidade: subjetividade em tempo de globalização. In: LINS, D. Cultura e subjetividade: saberes nômades. Campinas: Papirus, p.19-24,1997. SAMPAIO, M. N. Educação de jovens e adultos: uma história de complexidade e tensões. Práxis educacional. Vitória da Conquista, v. 5, n. 7, p. 13-27, 2009.

SZANTO, J. O. Psicologia e Educação de Jovens e Adultos: histórias de vida e caminhos percorridos pelos jovens que voltaram à escola. 2006. 182 f. Dissertação (Mestrado em Psicologia) - Instituto de Psicologia da Universidade de São Paulo, São Paulo, 2006. TAPETE Vermelho. Direção Luiz A. Pereira. São Paulo: Pandora Filmes, 2006. DVD. 
